\title{
Andreas Hoff (ed.) (2011). Population Ageing in Central and Eastern Europe. Societal and Policy Implications. Farnham, UK \& Burlington, VT, USA: Ashgate, 260 pp. ISBN 9780754678281 (hardback)
}

\section{REVIEWED by ANDRZEJ KLIMCZUK*}

Population ageing is one of the key challenges of many societies in the early $21^{\text {st }}$ century. In countries of former communist states of Eastern, South-Eastern and Central Europe this process takes place differently from Northern and Western Europe. The fact that these changes co-occur with the transformation of political, social and economic characteristics of individual countries towards liberal democracy and free market is crucial.

Population Ageing in Central and Eastern Europe. Societal and Policy Implications is a unique collection of scientific research papers involving comparative perspectives. A key thesis described by the editor Andreas Hoff in the preface and introduction chapter is that in Central and Eastern Europe, population ageing is determined by the joint effects of increasing longevity, a very rapid fall in fertility and migration of young Eastern Europeans from "accession countries" of the European Union to "old EU member states", which is associated with "EU enlargement" as well as migration to North America or Australia.

The book consists of 14 chapters prepared by leading scholars and researchers within the field of demography and gerontology. It is divided

*Andrzej Klimczuk, Warsaw School of Economics, Poland 
International Journal of Ageing and Later Life

into four sections. Importantly, they do not have short joint summaries. However, the concluding chapter of the book by Hoff is an inspiring summary of the main facts and recommendations for the whole region.

The first section concerns an ageing population of Eastern Europe. It includes chapters on Poland (by Ewa Fratczak), Lithuania (Sarmitė Mikulionienè) and Russia (Gaiane Safarova). The most important common problems which the authors point out are a much faster ageing process during the transition from the Soviet regime period, a delayed drop in mortality, gender inequality in ageing, emigration to old EU countries and negative image of elderly in public media discourse.

The second part of the book deals with Central-Eastern Europe and includes chapters on the Czech Republic (by Iva Holmerová, Hana Vaňková, Bozena Juraskova and Dana Hrnciiariková), Hungary (Zsuzsa Széman) and Slovenia (Valentina Hlebec and Milivoja Sircelj). In particular, a valuable part of this section is that it highlights the need to search for solutions to the problems that characterize also other countries in the region. For example, it includes some good practices that are used to reduce ageism, change seniors' roles in public life, eliminate early retirement culture, increase employment of older workers, improve social care and social support networks of older people.

The third section is on South-Eastern Europe and includes chapters on Croatia (by Sandra Švaljek), Romania (Ágnes Neményi) and Bulgaria (Emil Hristov). This section includes analysis of the conclusions on public pension and public health expenditures, changes in health care systems for the elderly, ageing in rural areas as well as a description of previous trends like postponement of pregnancies and high emigration.

The summary section of the volume concerns societal and policy implications of population ageing for all analysed countries. It contains chapters on physical and cognitive functions in older persons (by Martin Bobak, Hynek Pikhart and Michael Marmot), family relations and family care (Piotr Czekanowski), sustainability of demographic trends (Arjan Gjonça and Edlira Gjonça) and an overview of conclusions for all Eastern and Central European countries (Andreas Hoff). The section contains a comparative analysis of some Central and Eastern Europe, former Soviet Union and EU member states. Nevertheless, it is still important to extend geographical coverage of these studies to allow comparisons 
with other countries in the region as well as suggest policies to reduce social and health inequalities between them.

This volume is based mainly on analysis of demographic data. A significant advantage of the book is that authors use data reaching as back as the beginning of $20^{\text {th }}$ century, which allows for a better understanding of trends. Authors argue that the countries from the region have poor data on physical and cognitive function of older people and it is time to undertake appropriate research.

The book primarily provides an overview of the situation in individual countries of the region. More attention could be devoted to comparisons of international data on individual phenomena as well as recommendations, the possibility for cooperation of state and other actors (non-governmental and commercial organizations) in the field of early intervention.

It would be very interesting to consider supplementing the volume with the broader context of modernization, institutional and technological changes occurring in the analysed countries as well as to compare the existing government strategies and public policies to address the challenges of population ageing.

The book should be considered particularly interesting for demographers as well as researchers of social, political and economic transformation of Central and Eastern European countries. It stimulates the further deepening of research from comparative and regional perspectives. It will also be useful for those involved in the analysis of changes in family relations and family care. 